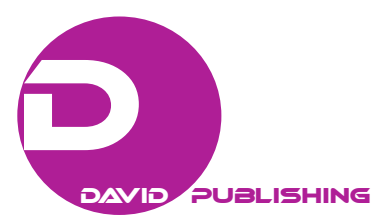

\title{
Academia Capabilities, Knowledge Transfer Programme Mechanism and Performance
}

\author{
Roselina Ahmad Saufi \\ Universiti Malaysia Kelantan (UMK), Kelantan, Malaysia \\ Zatul Karamah A. B. U. \\ Universiti Sultan Azlan Shah (USAS), Perak, Malaysia \\ Rosle Mohidin, Roslinah Mahmud \\ Universiti Malaysia Sabah (UMS), Sabah, Malaysia \\ Durrishah Idrus \\ Universiti Teknologi Malaysia (UTM), Johor, Malaysia
}

\begin{abstract}
Knowledge transfer (KT) is an attempt by an entity to copy and utilize an explicit type of knowledge from another entity. The main reason is none other than to expand the ability and increasing the value through inter-organization collaborative affiliation. Nonetheless, questions may arise as to what extent do capabilities, mechanism and performance or success is associated. Using inputs from 154 respondents which consist of various KTP (knowledge transfer program) partners namely from the community (total 94) and industry (total 60), this article highlights the associations between the three main categories of variables. Using Smart PLS (partial least squares), the study provides evidence that academia knowledge, academia readiness, academia skills, and ethics and conduct affect KTP performance through the mediation role of KT mechanism. Academia readiness was also found to be the most significant predictor to KT mechanism. In summary, all the significant capabilities have indirect positive impact towards KTP performance. Thus, higher education institutions must emphasize their internal strength in order to continue supporting the success of inter-organization collaborative affiliation.
\end{abstract}

Keywords: knowledge transfer, academia capabilities, KT mechanism, KT performance

\section{Introduction}

Knowledge transfer (KT) can be defined as an attempt by an entity to copy and utilize an explicit type of

Acknowledgements: The research is funded by the Knowledge Transfer Programme (KTP)—special research, Ministry of Higher Education, Malaysia. Project Code: UTM 4L517.

Roselina Ahmad Saufi, Ph.D., professor, Faculty of Entrepreneurship and Business, Universiti Malaysia Kelantan, Kelantan, Malaysia.

Zatul Karamah A. B. U., Ph.D., associate professor, Faculty of Business and Information Technology, Universiti Sultan Azlan Shah, Perak, Malaysia.

Rosle Mohidin, MBA, senior lecturer, Faculty of Business, Economics and Accountancy, Universiti Malaysia Sabah, Sabah, Malaysia.

Roslinah Mahmud, masters of Economics, lecturer, Faculty of Business, Economics and Accountancy, Universiti Malaysia Sabah, Sabah, Malaysia.

Durrishah Idrus, Ph.D., professor, International Business School, Universiti Teknologi Malaysia, Johor, Malaysia.

Correspondence concerning this article should be addressed to Roselina Ahmad Saufi, Faculty of Entrepreneurship and Business, Universiti Malaysia Kelantan, Kelantan 16100, Malaysia. 
knowledge from another entity (Rogers, 1983). KT has identified a myriad of factors that can influence the process and its outcomes, including the antecedents, processes, and mechanisms of knowledge transfer as well as barriers and consequences (When \& Montalvo, 2018). The objectives may also include to expanding the ability and increasing the value of an organization by collaborative affiliation (Davenport \& Prusak, 2000). Leydesdorff and Etzkowitz (1998) had highlighted the significant role of collaborative relationship between university, industry, and government through entrepreneurial and knowledge seeking activities while maintaining its common traditional role. However, the transfer of knowledge through inter-organization is neither an easy nor a costless task.

The process of transferring the knowledge may have to be gradually developed through vigorous and systematic learning efforts. Higher education provider (HEP) like universities, colleges, and polytechnics are seen as the focal point of multiple academia capabilities and are very much involved with the learning process and knowledge transfer. These capabilities may range from experience, knowledge, readiness, skills, ethics, and conduct. It can be shared and assigned via many ways and finally be able to determine the success of knowledge transfer program (KTP). The sharing mechanism may include collaboration, coaching, community of practice, and facilitated training. The KTP success can be demonstrated either by financial performance, improvement in knowledge, and skills. But to what extend does all these capabilities, mechanisms, and success be associated? Though several studies have highlighted the factors that influence KTP success, limited studies address the relationship between academia capabilities, KTP mechanisms, and its success simultaneously.

The next section of this paper highlights the research objectives. This is followed by the research context in relation to existing literature, research framework, and summary of hypotheses. Subsequent sections deal with methodology, data analysis, path analysis, and hypotheses testing. The final section is on discussion and conclusion with future research suggestions.

\section{Research Objectives}

This paper attempts to examine three main objectives:

(1) To identify the influence of academia capabilities towards knowledge transfer mechanism.

(2) To determine the most significant predictor of knowledge transfer mechanism.

(3) To quantify the relationship between knowledge transfer mechanism and knowledge transfer performance.

\section{Review of Literature}

Nonaka and Takeuchi's (1995) model highlighted that knowledge transfer consists of four main categories namely socialization, externalization, combinations, and internalization (SECI). The model defines socialization as the direct interaction between external and internal of individual to an organization. This interaction can be done by sharing experiences which may result in acquiring new skills. Externalization happens when individuals in a group interact actively communicate between each other to share their beliefs. The face-to-face interaction provides common platform for members to learn, share instant feedback, and exchange ideas simultaneously. Combination of the knowledge transfer process occurs among groups across an organization and it can be enhanced through information technology assistance. On the other hand, internalization involves understanding and absorbing the explicit knowledge into tacit knowledge. The process 
can be realised via actual doing or simulations. In today's world, the transfer of the explicit knowledge can be completed, using email and databases as well as the conventional way using briefings and meetings.

\section{Academia Capabilities}

Experience. Kathoefer and Leker (2012) documented that this academia experience provides significant impact on KT projects. The sustainability and survival of an organization increases if they have more experience and more adaptable to the process (Argote, Ingram, Levine, \& Moreland, 2000). Exposure to and experience in the actual industry or community setting will make the process of knowledge transfer more effective.

Knowledge. Statistical evidence by Laudry, Amara, and Ouitmet (2007) indicated that differences in levels of knowledge activities across research fields are important. However, a study by Kathoefer and Leker (2012) on barriers toward knowledge transfer found that although universities continue to play vital role in the knowledge society, knowledge particularly on research discipline did not actually have significant influence on KT projects. This condition will definitely influence the linkages between researchers and research users.

Readiness. Siemieniuch and Sinclair (2004) proposed that an effective knowledge transfer occurs when one party readiness to transfer knowledge can be matched with the receptive level of an organizational. In this manner, intensity level of knowledge transfer mechanism of enterprises should fit to the type of knowledge. This paper suggests that readiness of the academia to be able to collaborate with this industry or community is essential especially in terms of cognitive stability and readiness.

Skills. Advances in knowledge transfer in organization can be supported by the diversity of involved parties in engaging different task, tools, networks, and work synergy (Argote et al., 2000; Argote \& Fahrenkopf, 2016; Argote, Aven, \& Kush, 2018). Another consideration within this perspective is the ability of an organization to innovate successfully. Innovation, which can be adapted to complexity in an organization, is seen to work closely with technological support (Gilbert \& Cordey-Hayes, 1996). This capability, which can be classified as a source of competitive advantage, may improve organizational performance especially to entrepreneurship domain. Academia skill refers to competencies' level acquires by the academia in using any tool, procedure, or technology, and applying the knowledge to the industry/community recipient.

Ethics and conduct. It is interesting to note that ethics of KT can be managed from two perspectives of knowledge (Baskerville \& Dulipovici, 2006). Firstly, organizational knowledge falls under the theory of intellectual property and secondly; personal knowledge falls under personal privacy theory. The impact for which the former, organizations have the right to buy, sell, and use their corporate knowledge that best suits their needs, while the latter, it is the individuals who have the right to protect the security of their knowledge.

According to Laudry et al. (2007), the process of transferring knowledge will happen more actively when no commercialisation was involved rather than when there was commercialization of protected intellectual property. In fact, different policies have significant influence when different research fields are involved in the process especially when the transfer of information is done informally and unauthorized. Similar findings can also be referred to Kathoefer and Leker (2012) and Koulikov (2011).

\section{KT Mechanism}

The mechanism for KT may include collaboration, coaching, community of practice, and facilitated training (Simonin, 1999). Argote et al. (2000) and Gera (2012) highlighted that the support from the human resource management at workplace can minimize and in fact may be able to eliminate knowledge transfer gaps. This will later lead to improvise the performance. 


\section{Research Framework and Hypotheses}

The background of the literature provide support to the formulation of the research framework for examining the relationship between academia capabilities, namely their experience, knowledge, readiness, skills, and ethics and conduct, and the performance of knowledge transfer programme conducted by the public universities in Malaysia (see Figure 1).

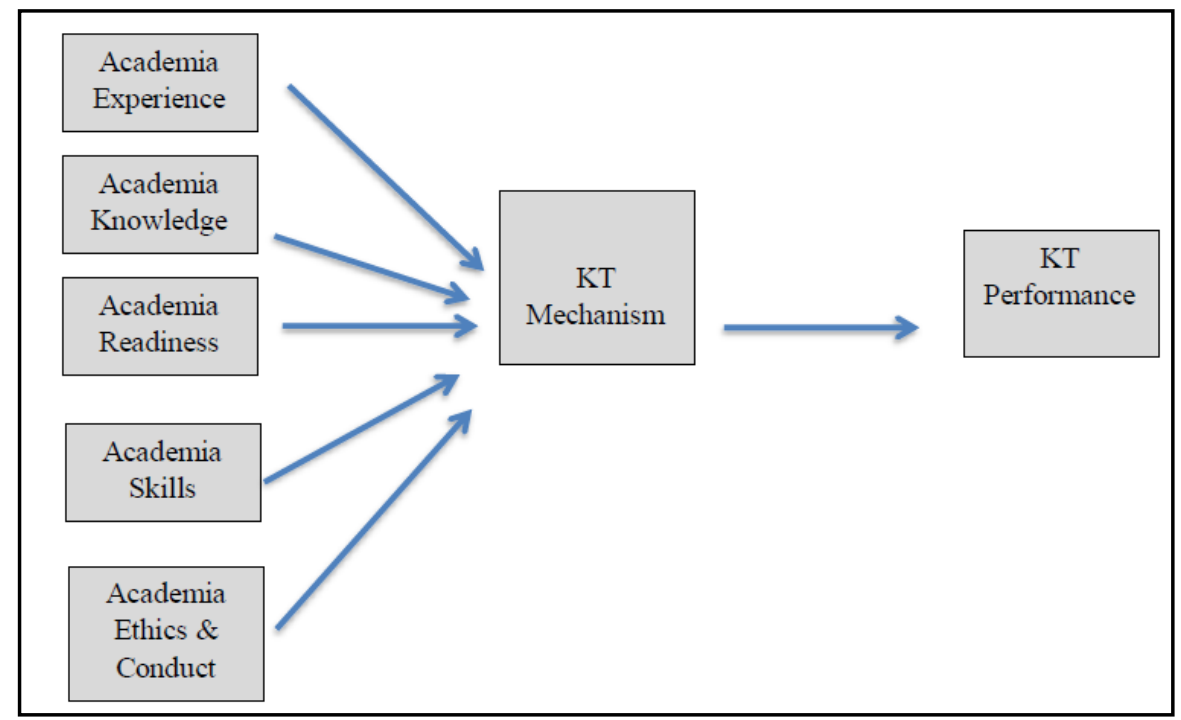

Figure 1. Research framework.

The summary of hypotheses for this study is as follows:

Table 1

Research Hypotheses Summary

\begin{tabular}{|l|l||}
\hline H1 & $\begin{array}{l}\text { Experience of the academia has a direct positive effect on the mechanism of } \\
\text { knowledge transfer programme. }\end{array}$ \\
\hline H2 & $\begin{array}{l}\text { Knowledge of the academia has a direct positive effect on the mechanism of } \\
\text { knowledge transfer programme. }\end{array}$ \\
\hline H3 & $\begin{array}{l}\text { Readiness of the academia has a direct positive effect on the mechanism of } \\
\text { knowledge transfer programme. }\end{array}$ \\
\hline H4 & $\begin{array}{l}\text { Skills of the academia has a direct positive effect on the mechanism of } \\
\text { knowledge transfer programme. }\end{array}$ \\
\hline H5 & $\begin{array}{l}\text { Ethics and Conduct of the academia has a direct positive effect on the } \\
\text { mechanism of knowledge transfer programme.. }\end{array}$ \\
\hline H6 & $\begin{array}{l}\text { The knowledge transfer mechanism is positively related to the performance } \\
\text { of knowledge transfer programme.. }\end{array}$ \\
\hline
\end{tabular}

\section{Data and Methodology}

\section{Respondents}

The list of the expected respondents is provided by the Secretariat of the National Centre for Knowledge Transfer Programme at the Universiti Sains Malaysia. As at 2017, there were 485 KT projects approved to all the 20 public universities in Malaysia. For collecting specific information from a specific group, the purposive sampling is applied (Etikan, Musa, \& Alkassim, 2016). The unit of analysis in this study is the 
community-partners and industry-partners for KTP Research Grant awarded to the selected 11 public universities in Malaysia between 2011 and 2015. These partners are mainly from agriculture, health and natural sciences, tourism, entrepreneurship, and education sectors.

\section{Data Collection Instrument and Management}

The research instrument is based on questionnaire that was constructed by using five-point Likert Scale. The foundations of the questionnaire were based on previous studies done by Ken and Cheah (2012), Schofield (2013), and Shah and Chenicheri (2011). In total, 254 questionnaires were distributed for gathering data from the respondents as highlighted in previous section "Respondents". The data collection period, which took almost three months, was employed using multiple methods in that some were personally administered, and others were e-mailed. SPSS version 23 is used for preliminary data management that includes coding and descriptive outputs. Smart PLS 3.0 is then utilized to test all the hypotheses for this study.

\section{Goodness of Measures Assessment}

The criteria used for assessing the goodness of measures in this research are validity and reliability. As mentioned by Sekaran and Bougie (2016), validity tests to what extent the developed instrument measures a particular concept and it is intended to measure. Construct validity in particular tests how well the output results gathered for the use of the measure fit the theories around which the test is designed. It is more appropriate to be used in social sciences studies (Cronbach \& Meehl, 1955). In fact, construct validity highlights whether the instrument tap the concept as theorized based on convergent validity and discriminant validity.

Validity tests. Next is the testing for convergent validity. It determines the extent to which multiple items measure the same construct. It is accessed by factor loadings, composite reliability, and average variance extracted (AVE). Composite reliability measures the degree to which the construct indicators specify the latent, while AVE depicts the average variance shared between indicators/constructs and its measurement error. The recommended value for loadings is greater than 0.5 (Hair, Black, Babin, \& Anderson, 2010; Hair, Hult, Ringle, $\&$ Sarstedt, 2017), for composite reliability is more than 0.7 (Hair et al., 2010) and for AVE must be greater or equal to 0.50 (Barclay, Thompson, \& Higgins, 1995; Hair, Ringle, \& Sarstedt, 2013).

For discriminant validity, it measures the degree to which items differentiate among construct or in order words, the uniqueness of a construct (Hair et al., 2013). And based on Fornel-Larcker criterion, it is accessed by looking at the cross loadings among constructs or correlations between the any potential overlapping constructs measure. First assessment is to observe that the loadings of the construct should be strong on itself and low on other constructs. Second assessment is to compare the square root of the AVE values with the latent variables correlations. The squared root shared between each construct and its measures should be greater than its squared root shared between the construct and other constructs (Compeau, Higgins, \& Huff, 1999; Fornel \& Larcker, 1981).

Reliability tests. Reliability evaluates the consistency of the measuring instrument towards whatever concept it is measuring (Hair et al., 2010; Hair et al., 2017). It is tested based on: (1) Cronbach's alpha; and (2) composite reliability. The coefficient for Cronbach's alpha shows the measurement of inter item consistency. The acceptable value for the alpha is 0.6 or more (Nunnally \& Beinstein, 1994). Compared to Cronbach's alpha, composite reliability refers to individual reliability. For the latter, a value of 0.70 or greater is considered acceptable (Fornell \& Larcker, 1981). Henseler and Sarstedt (2013) considered a score more than 0.6 as an acceptable value for composite reliability. 


\section{Hypotheses Testing}

Path analysis provides the results for hypotheses testing. The coefficient and $t$-values highlight whether the variables are significantly related either in positive manner or otherwise. In addition, the $R^{2}$ value in the model shows whether the variables can be explained in each tested relationship.

\section{Analysis Results}

\section{Summary of Respondents}

As highlighted in Figure 2, a total of 154 respondents which consist of various KTP partners namely from the community (total 94) and industry (total 60) are interviewed. In all, a response rate of $61 \%$ is recorded. Universiti Putra Malaysia (UPM) [30\%] records the highest number of total respondents while the lowest number is Universiti Pertahanan Nasional Malaysia (UPNM) scored 0.6\%. UPM also provides the highest number of respondents for both community-partners as well as industry-partners.

\section{Convergent Validity}

Table 2 showed that the loadings for all items are above the value of 0.5 as recommended by Hair et al. (2010). The composite reliability (CR) ranged from 0.853 to 0.952 . These values also exceeded the recommended value of 0.7 (Hair et al., 2010). The values for AVE also justified the condition where the average variance shared between a construct and its measures should be greater than that shared with other constructs within similar model. It is observed that the values are also higher than 0.5 where its range is from 0.672 (academia knowledge) to 0.865 (academia experiences).

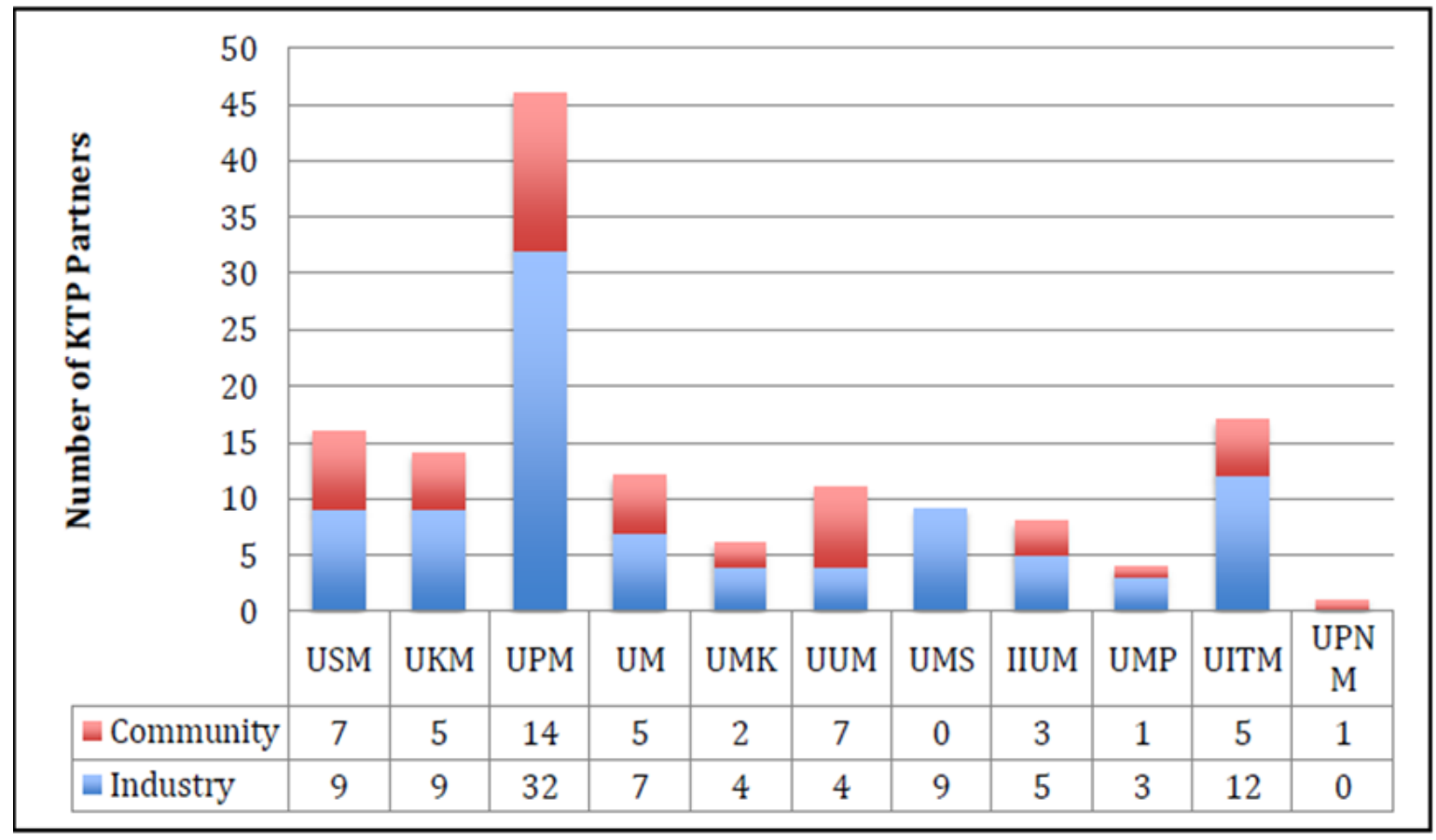

Figure 2. Number of respondents segregated by university.

Notes. USM-Universiti Sains Malaysi; UMS-Universiti Malaysia Sabah; UMK-Universiti Malaysia Kebangsaan; IIUM-International Islamic University Malaysia; UPM-Universiti Putra Malaysia; UMP-Universiti Malaysia Perlis; UM-Universiti Malaya; UITM-Universiti Teknologi MARA; UMK-Universiti Malaysia Kelantan; UPNM-Universiti Pertahanan Nasional Malaysia; UUM-Universiti Utara Malaysia. 


\section{Reliability Analysis}

Referring to Table 2, the Cronbach's alpha (CA) coefficients exceeded the value of 0.6 (Nunnally \& Berstein, 1994). All the composite reliability values which higher than 0.70 (Fornell \& Larcker, 1981). Thus, it can be concluded that the measurements are reliable.

Table 2

Result of Measurement Model

\begin{tabular}{|c|c|c|c|c|c|}
\hline $\begin{array}{c}\text { Latent } \\
\text { Variables }\end{array}$ & Items & $\begin{array}{c}\text { Factor } \\
\text { Loadings }\end{array}$ & $\mathrm{CA}$ & CR & AVE \\
\hline Academia & PC11 & 0.943 & & & \\
\hline Experiences & $\mathrm{PC} 12$ & 0.917 & 0.845 & 0.928 & 0.865 \\
\hline \multirow{3}{*}{$\begin{array}{l}\text { Academia } \\
\text { Knowledge }\end{array}$} & PC21 & 0.516 & \multirow{3}{*}{0.801} & \multirow{3}{*}{0.853} & \multirow{3}{*}{0.672} \\
\hline & $\mathrm{PC} 22$ & 0.925 & & & \\
\hline & $\mathrm{PC} 23$ & 0.945 & & & \\
\hline \multirow{6}{*}{$\begin{array}{l}\text { Academia } \\
\text { Readiness }\end{array}$} & PC31 & 0.836 & \multirow{6}{*}{0.938} & \multirow{6}{*}{0.952} & \multirow{6}{*}{0.769} \\
\hline & PC32 & 0.892 & & & \\
\hline & PC33 & 0.878 & & & \\
\hline & PC34 & 0.723 & & & \\
\hline & PC35 & 0.939 & & & \\
\hline & PC36 & 0.971 & & & \\
\hline \multirow{5}{*}{$\begin{array}{l}\text { Ethics \& } \\
\text { Conduct }\end{array}$} & PC41 & 0.821 & \multirow{5}{*}{0.890} & \multirow{5}{*}{0.909} & \multirow{5}{*}{0.722} \\
\hline & $\mathrm{PC} 42$ & 0.923 & & & \\
\hline & $\mathrm{PC} 44$ & 0.873 & & & \\
\hline & $\mathrm{PC} 45$ & 0.945 & & & \\
\hline & PC46 & 0.810 & & & \\
\hline \multirow{4}{*}{$\begin{array}{l}\text { Academia } \\
\text { Skills }\end{array}$} & PC51 & 0.904 & \multirow{4}{*}{0.926} & \multirow{4}{*}{0.943} & \multirow{4}{*}{0.768} \\
\hline & PC52 & 0.572 & & & \\
\hline & PC54 & 0.963 & & & \\
\hline & PC56 & 0.903 & & & \\
\hline \multirow{6}{*}{$\begin{array}{c}\text { KT } \\
\text { Mechanism }\end{array}$} & $\mathrm{PH} 22$ & 0.745 & \multirow{6}{*}{0.920} & \multirow{6}{*}{0.939} & \multirow{6}{*}{0.721} \\
\hline & PH31 & 0.923 & & & \\
\hline & $\mathrm{PH} 32$ & 0.849 & & & \\
\hline & PH33 & 0.969 & & & \\
\hline & PH41 & 0.898 & & & \\
\hline & $\mathrm{PH} 42$ & 0.675 & & & \\
\hline \multirow{5}{*}{$\begin{array}{c}\text { KT } \\
\text { Performance }\end{array}$} & PJ2 & 0.734 & \multirow{5}{*}{0.923} & \multirow{5}{*}{0.933} & \multirow{5}{*}{0.738} \\
\hline & PJ3 & 0.805 & & & \\
\hline & PJ4 & 0.902 & & & \\
\hline & PJ5 & 0.933 & & & \\
\hline & PJ6 & 0.904 & & & \\
\hline
\end{tabular}

\section{Discriminant Validity}

As shown in Table 3, it is proven that the AVE values (highlighted in bold) by the indicators measuring that constructs are higher than the squared correlations for each construct. In all, both evidences from "Convergent Validity" and "Reliability Analysis" verified that the measurement model demonstrated adequate convergent validity and discriminant validity.

\section{Hypotheses Testing}

Both Figure 3 and Table 4 provided statistical evidences for the hypotheses testing. 
Table 3

Discriminant Validity of Construct (Fornell and Larcker Method)

\begin{tabular}{|c|c|c|c|c|c|c|c|}
\hline Latent Variables & 1 & 2 & 3 & 4 & 5 & 6 & 7 \\
\hline $\begin{array}{ll}\text { 1. Academia } \\
\text { Experience }\end{array}$ & 0.930 & & & & & & \\
\hline $\begin{array}{l}\text { 2. Academia } \\
\text { Knowledge }\end{array}$ & 0.389 & 0.821 & & & & & \\
\hline $\begin{array}{l}\text { 3. Academia } \\
\text { Readiness }\end{array}$ & 0.827 & 0.480 & 0.877 & & & & \\
\hline 4. Academia Skills & 0.401 & 0.191 & 0.444 & 0.850 & & & \\
\hline 5. Ethics \& Conduct & 0.854 & 0.475 & 0.814 & 0.481 & 0.876 & & \\
\hline 6. KT Mechanism & 0.722 & 0.624 & 0.898 & 0.488 & 0.795 & 0.849 & \\
\hline 7. KT Performance & 0.780 & 0.268 & 0.837 & 0.495 & 0.813 & 0.650 & 0.860 \\
\hline
\end{tabular}

Note: Diagonals represent the square root of the $A V E$ while the other entries represent the correlations

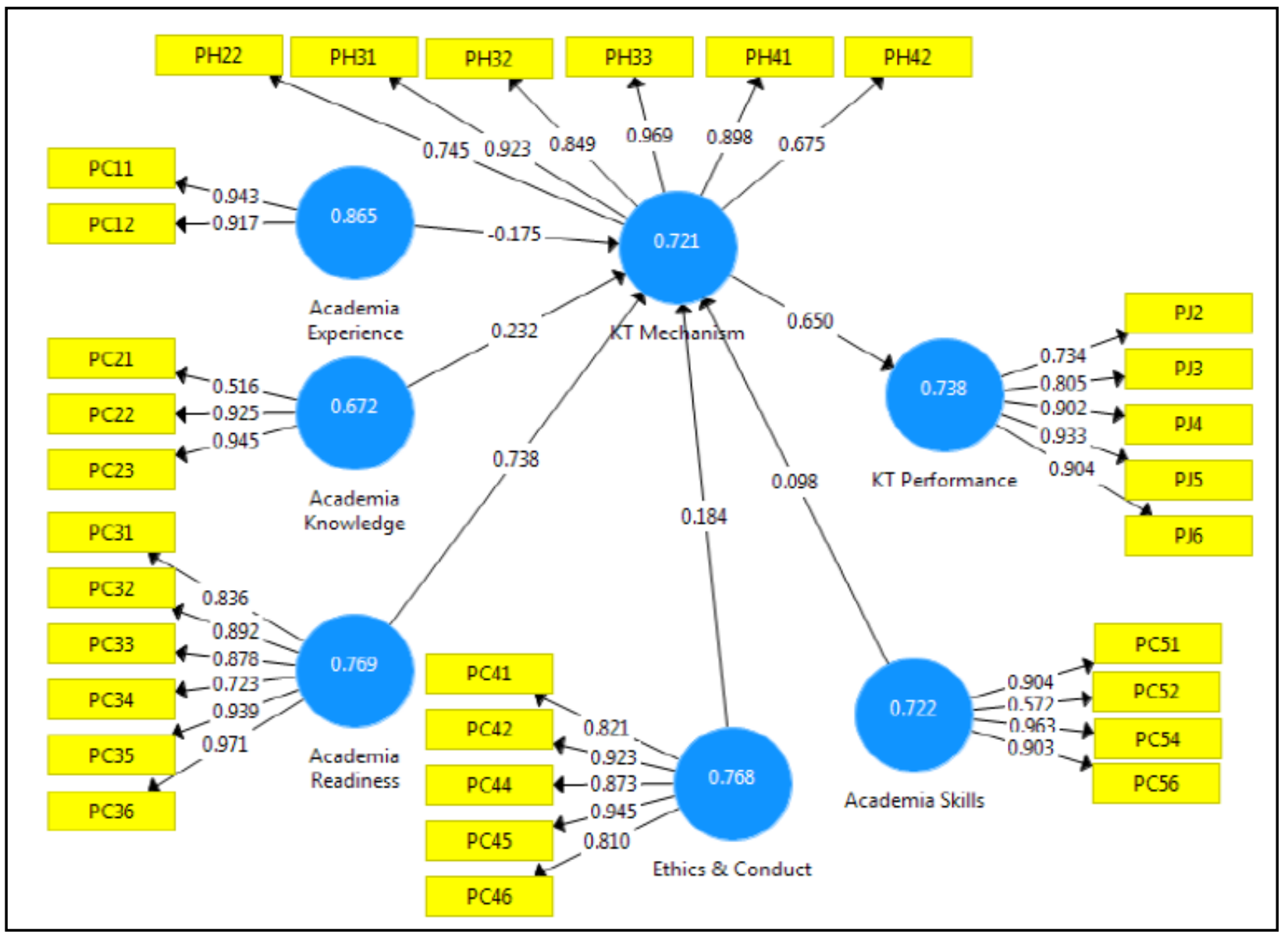

Figure 3. Path analysis results.

The $R^{2}$ value of 0.721 suggested that $72.1 \%$ of the variance of KT mechanism can be explained by academia knowledge, academia readiness, academia skills, and academia ethics and conduct. It is also clearly indicated that all four are positively significant where the coefficients are $0.232(p<0.01), 0.738(p<0.01)$, $0.098(p<0.05)$, and $0.184(p<0.01)$ respectively. Nonetheless, academia experience did not share the same trait where it was not a significant predictor for KT mechanism. Thus, H2, H3, H4, and H5 are supported except for $\mathrm{H} 1$ (see Table 4). 
H6 was also supported as the $R^{2}$ value is recorded at 0.738 . The result indicated that $73.8 \%$ of the variance in KTP performance could be explained by KT mechanism. In fact, a positive relationship between these two can be observed $(\beta=0.650, p<0.01)$. Hence, the outputs of the study provide evidence that academia knowledge, academia readiness, academia skills, and academia ethics and conduct affect KT performance through the mediation role of KT mechanism. In this study, it was observed that academia readiness was the most significant predictor to KT mechanism.

Table 4

Path Coefficient and Hypothesis Testing

\begin{tabular}{lccc}
\hline \multicolumn{1}{c}{ Relationship } & Coefficient & T-Value & Supported \\
\hline $\begin{array}{l}\text { Academia Experiences } \rightarrow \text { KT } \\
\text { Mechanism }\end{array}$ & -0.175 & 2.466 & No \\
Academia Knowledge -> KT Mechanism & 0.232 & $5.607^{* *}$ & Yes \\
Academia Readiness -> KT Mechanism & 0.738 & $13.316^{* *}$ & Yes \\
Academia Skills -> KT Mechanism & 0.098 & $2.130^{*}$ & Yes \\
Ethics \& Conduct -> KT Mechanism & 0.184 & $2.530^{* *}$ & Yes \\
KT Mechanism -> KTP Performance & 0.650 & $25.214^{* *}$ & Yes \\
\hline
\end{tabular}

Note: ${ }^{*} p=0.05 ;{ }^{*}{ }^{*} p=0.01$

This paper highlights three main objectives, namely the influence of academia capabilities towards the KT mechanism, the most significant predictor for KT mechanism, and the relationship between KT mechanism and KT performance. It can be summarized that four independent variables-academia knowledge, academia readiness, academia skills, and academia ethics and conduct affect KT performance through the mediation role of KT mechanism. Among the four variables, academia readiness is found to be the most significant predictor for KT mechanism with all significant capabilities' items showed indirect positive impact towards KT performance. The study thus implies that higher education institutions must emphasize their internal strength in order to continue supporting the success of inter-organization collaborative affiliation. Academia capabilities must be continuously developed to ensure effective implementation of knowledge transfer programme.

\section{References}

Argote, L., \& Fahrenkopf, E. (2016). Knowledge transfer in organizations: The roles of members, tasks, tools and networks. Organizational Behavior and Human Decision Processes, 136(C), 146-159.

Argote, L., Aven, B., \& Kush, J. A. (2018). The effects of communication networks and turnover on transactive memory and group performance. Organization Science, 29(2), 191-201.

Argote, L., Ingram, P., Levine, J. M., \& Moreland, R. L. (2000). Knowledge transfer in organizations: Learning from the experience of others. Organizational Behavior and Human Decision Processes, 82(1), 1-8.

Barclay, D., Thompson, R., \& Higgins, C. (1995). The partial least squares (PLS) approach to causal modeling: Personal computer adoption and use an illustration. Technology Studies, 2(2), 285-309.

Baskerville, R., \& Dulipovici, A. (2006). The theoretical foundations of knowledge management. Knowledge Management Research \& Practice, 4, 83-105.

Compeau, D. R., Higgins, C. A., \& Huff, S. (1999). Social cognitive theory and individual reactions to computing technology: A longitudinal-study. MIS Quarterly, 23(2), 145-158.

Cronbach, L. J., \& Meehl, P. E. (1955). Construct validity in psychological tests. Psychological Bulletin, 52, 281-302.

Davenport, T., \& Prusak, L. (2000). Working knowledge: How organizations manage what they know. Boston: Harvard Business School Press. 
Etikan, I., Musa, S. A., \& Alkassim, R. S. (2016). Comparison of convenience sampling and purposive sampling. American Journal of Theoretical and Applied Statistics, 5(1), 1-4.

Fornell, C., \& Larcker, D. F. (1981). Evaluating structural equation models with unobservable variables and measurement error. Journal of Marketing Research, 18(1), 39-50.

Gera, R. (2012). Bridging the gap in knowledge transfer between academia and practitioners. International Journal of Educational Management, 26(3), 252-273.

Gilbert, M., \& Cordey-Hayes, M. (1996). Understanding the process of knowledge transfer to achieve successful technological innovation. Technovation, 16(6), 301-312.

Hair, J. F., Hult, G. T. M., Ringle, C. M., \& Sarstedt, M. (2017). A primer on partial least squares structural equation modeling (PLS-SEM) (2 ed.). Thousand Oaks, CA: Sage.

Hair, J. F., J. R., Black, W. C., Babin, B. J., \& Andersen, R. E. (2010). Multivariate data analysis (7th ed.). Upper Saddle River, NJ: Pearson Prentice Hall.

Hair, J. F., Ringle, C. M., \& Sarstedt, M. (2013). Partial least squares structural equation modeling: Rigorous applications, better results and higher acceptance. Long Range Planning, 46, 1-12.

Henseler, J., \& Sarstedt, M. (2013). Goodness-of-fit indices for partial least squares path modeling. Computational Statistics, 28(2), 565-580.

Kathoefer, D. G., \& Leker, J. (2012). Knowledge transfer in academia: An exploratory study on the not-invented-here syndrome. The Journal of Technology Transfer, 37(5), 658-675.

Ken, T., \& Cheah, Y. (2012). Business graduates' competencies in the eyes of employers: An exploratory study in Malaysia. World Review of Business Research, 2(2), 176-190.

Koulikov, M. (2011). Emerging problems in knowledge sharing the three new ethics of knowledge transfer. Knowledge Management \& E-Learning: An International Journal (KM \& EL), 3(2).

Laudry, R., Amara, N., \& Ouimet, M. (2007). Determinants of knowledge transfer: Evidence from Canadian university researchers in natural sciences and engineering. The Journal of Technology Transfer, 32(6), 561-592.

Leydesdorff, L., \& Etzkowitz, H., (1998). The triple helix as a model for innovation studies. Science and Public Policy, 25(3), 195-203.

Nonaka, I., \& Takeuchi, H. (1995). The knowledge-creating company: How Japanese companies create the dynamics of innovation. New York, NY: Oxford University Press.

Nonaka, I., Toyama, R., \& Hirata, T. (2008). Managing flow: A process theory of the knowledge-based firm. New York: Palgrave MacMillan.

Nonaka, I., Toyama, R., \& Komo, N. (2000). SECI, Ba and leadership: A unified model of dynamic knowledge creation. Long Range Planning, 33, 5-34.

Nunnally, J. C., \& Bernstein, I. H. (1994). Psychometric theory. New York: McGraw.

Rogers, E. (1983). The diffusion of innovation. New York: Free Press.

Schofield, T. (2013). Critical success factors for knowledge transfer collaborations between university and industry. Journal of Research Administration, 44(2).

Sekaran, U., \& Bougie, R. (2016). Research methods for business: A skill-building approach (7th ed.). Haddington: John Wiley \& Sons.

Shah, M., \& Chenicheri, S. N. (2011). Employer satisfaction of university graduates: Key capabilities in early career graduates. In Developing student skills for the next decade: Proceedings of the 20th Annual Teaching Learning Forum, February1-2. Edith Cowan University, Perth. Retrieved from http://goo.gl/TRX6kO

Siemieniuch, C. E., \& Sinclair, M. A. (2004). A framework for organizational readiness for knowledge management. International Journal of Operations and Production Management, 24(1), 79-98.

Simonin, B. L. (1999). Ambiguity and the process of knowledge transfer in strategic alliances. Strategic Management Journal, 22(7), 595-623.

Wehn, U., \& Montalvo, C. (2018). Knowledge transfer dynamics and innovation: Behaviour, interactions and aggregated outcomes. Journal of Cleaner Production, 171, 56-68. 